\title{
Study of Chinese Enterprises' Overseas M \& A: Based on National and Corporate Cultural Distance
}

\author{
Bo Xu, Xi Jiang \\ Management School, Shanghai University of International Business and Economics, Shanghai, China \\ Email: brianxubo@163.com, iiangxi-219@163.com
}

Received May 2014

\begin{abstract}
Chinese enterprises' overseas $M$ \& A reached \$43.4 billion in 2012, and the number was 26.3 times that of 2003. With Chinese enterprises' increased overseas $M \& A$ cases, Chinese are facing the challenges from culture. This paper studies national cultural distance and enterprise culture distance, and measure relevant distance for 16 Chinese $M \& A$ cases.
\end{abstract}

\section{Keywords}

Overseas M \& A, National Cultural Distance, Corporate Cultural Distance

\section{Introduction}

AS it can be seen from Table 1, in 2003, Chinese foreign investment was just $\$ 2.85$ billion. But by 2012, the scale reached $\$ 87.8$ billion, which was 30.8 times larger than that of 2003. In 2003, Chinese overseas M \& A volume was only $\$ 1.65$ billion. By 2012, the amount has reached $\$ 43.4$ billion, and the number was 26.3 times that of 2003. Data have shown that, China enterprises are stepping out, this is not only reflected in the newly foundation, but also in overseas $\mathrm{M} \& \mathrm{~A}$.

According to the UNCTA Report 2013, a great number of M \& A in the 211 cases (which money amounts were above $\$ 500$ million) failed because of competition, national security review, and cultural differences. These kinds of failure reached $\$ 265$ billion. In 2012, failed cases due to cultural issues accounted for $22 \%$; the number once peaked to $30 \%$ in 2010 [1].

The history of Chinese overseas M \& A is not long, yet Chinese enterprises are still facing the risk of failure. According to UNCTA, the failure rate of Chinese M \& A is $11 \%-12 \%$. Report "Chinese Enterprises, Global Dream" written by Accenture, suggested that there are five major obstacles hindering the expansion of enterprises. One of the barriers is the difficulty of establishing consistent values worldwide. As to Thomson Reuters' report, the failed $\mathrm{M} \&$ As directly or indirectly led by cultural problems account for $80 \%$. This shows that cross-cultural factor is an important cause of Chinese enterprises' overseas M \& A failure.

After these years' practices, Chinese enterprises realize the cultural gap between different countries. In this context, the measurement of cultural distance will help to understand the national cultural difference and corporate 
Table 1. Chinese FDI and M \& A Performance (2003-2012) (USD B).

\begin{tabular}{cccc}
\hline Year & FDI (A) & Overseas M\&A (B) & B/A (\%) \\
\hline 2003 & 2.85 & 16.5 & 57.8 \\
2004 & 5.5 & 30.0 & 54.5 \\
2005 & 12.26 & 65.0 & 53.0 \\
2006 & 21.16 & 82.5 & 39.0 \\
2007 & 26.51 & 63.0 & 23.8 \\
2008 & 55.91 & 302.0 & 54.0 \\
2009 & 56.53 & 192.0 & 34.0 \\
2010 & 68.81 & 297.0 & 43.2 \\
2011 & 7465 & 272.0 & 36.4 \\
2012 & 877.9 & 434.0 & 49.4 \\
\hline
\end{tabular}

Source: 2003-2012 Statistical Bulletin of China’s Outward Foreign Direct Investment; 2003 UNCTAD World Investment Report.

cultural difference. Those can also help to lower the risks from cultural differences.

\section{Literature Review}

\subsection{Cultural Distance}

Luostarinen firstly proposed the concept of cultural distance in 1980, and gave the following explanation [2]: the cultural distance can create demand for knowledge, and can also hinder the exchange of knowledge. Professor Lee combined cultural distance and psychological distance, and proposed that those distances represented the differences in language, social policy, and organization structure [3].

Scholars have two different points of view for cultural distance. Berry (1983), Nahavandi \& Malekzadeh (1988), Dension (2001) argued that cultural distance lead to success, because similar culture reduce employee concerns and resistance. But there were scholars think long cultural distance is beneficial. Adler found if effectively managed, high cultural distance also can promote the performance.

\subsection{National Cultural Distance (NCD) Measurement}

Hofstede is the authority of national culture. Therefore, the national cultural distance data are sourced from him. Hofstede built cultural dimension theory: power distance (PDI), individualism and collectivism (IDV), masculine and feminine (MAS), uncertainty avoidance (UAI), long-term orientation and short-term orientation (LTO). By scoring the five dimensions countries' culture has been measured.

In the method of measuring, there are four main kinds of claims:

(1) Laszlo's distance calculation formula (Equation (1)) [4]:

$$
\mathrm{CD}_{\mathrm{i}}=\sum_{5}^{i=1}\left[\left(I_{i j}-I_{i u}\right)^{2} / V_{i}\right] / 5
$$

$\mathrm{U}$ : mother country; $\mathrm{CD}_{\mathrm{j}}$ : cultural distance between country u and Coutry $\mathrm{j}$; $\mathrm{I}_{\mathrm{iu}}$ : country u's score in dimension $\mathrm{I} ; \mathrm{V}_{\mathrm{i}}$ : the variance of dimension $\mathrm{i}$.

(2) Qu Xiaoru's distance calculation formula (Equation (2)) [5]:

$$
\mathrm{CD}=\sqrt{\left(\mathrm{C}_{1}^{1}-\mathrm{C}_{0}^{1}\right)^{2}+\left(\mathrm{C}_{1}^{2}-\mathrm{C}_{0}^{2}\right)^{2}+\ldots+\left(\mathrm{C}_{1}^{5}-\mathrm{C}_{0}^{5}\right)^{2}}
$$

$\mathrm{C}_{\mathrm{i}}^{1}-\mathrm{C}_{\mathrm{i}}^{5}$ : dimension i's cultural score $(\mathrm{i}=1,2,3 \ldots), \mathrm{C}_{0}^{1}-\mathrm{C}_{0}^{5}$ : mother country's cultural score.

(3) Kogut and Singh's distance calculation formula (Equation (3)) [6]:

$$
\mathrm{CD}_{\mathrm{j}}=\sum_{4}^{i=1}\left[\left(I_{i j}-I_{i u}\right)^{2} / V_{i}\right] / 4
$$

$\mathrm{CD}_{\mathrm{j}}$ : cultural distance between country u and Coutry $\mathrm{j}$; $\mathrm{I}_{\mathrm{iu}}$ : country u's score in dimension $\mathrm{I} ; \mathrm{V}_{\mathrm{i}}$ : the variance of dimension i. 
(4) Morosini and Shane's distance calculation formula (Equation (4)):

$$
\mathrm{CD}_{\mathrm{j}}=\sqrt{\sum_{4}^{\mathrm{i}=1}\left\{\left(\mathrm{I}_{\mathrm{ij}}-\mathrm{I}_{\mathrm{iu}}\right)^{2}\right\}}
$$

It is worthy to emphasize, the last two methods, only use four cultural dimensions. The main reason is that at the time of conducting research, Hofstede had not come the fifth dimensions long vs. short term orientation (LTO). We can clearly see that the first, third and forth kinds of methods have the same ideas. So the thesis will follow this way, while taking into the fifth cultural dimensions [7].

\subsection{Corporate Cultural Distance (CCD) Measurement}

In the quantitative analysis area, there are several representatives which use questionnaire survey and statistics.

a, OCAI scale:

Quinn and Rohrbaugh raised OCAI (OCAI, Organizational Cultural Assessment Instrument). It is based on the competing values framework and competing values model. According to the survey, there were obvious differences in organizational effectiveness, organizational strategy, and decision process. The argument existed that whether the existing dimensions can be completely covered all aspects of corporate culture?

b, OCP scale

Professor Chatman from the University of California defined organizational culture as members of the shared value system. He built the organizational values scale (OCP scale) [8]. However, due to the OCP scale's no descriptive topic specific stem, interviewees need to know the testing professionals and need to be trained.

c, MMOC enterprise culture model

MMOC (Multidimensional Model of Organizational Culture) model was founded by Hofstede. The qualitative measurement methods are based on the collective values and practices. This culture model is worthy of being discussed in the place where, missing the questionnaire as recognized customer oriented, innovation of the academic value dimension. Secondly, some descriptions were too vague, which may give respondents confusion.

d, DOCQ scale

Professor Denison constructed DOCS scale (Denison Organization Culture Survey). Denison makes full use of the convenience of the network, through the establishment of a dedicated website: www.denisonculture.com, to collect data. DOCS' answers were scored by Likert method. This model provides enterprises with a total of four kinds of culture-adaptability, consistency, participation, and mission. Each kind of cultural traits corresponds to three dimensions, each dimension corresponds to the 5 problem.

e, Domestic study

Taiwan psychology professor Zheng Boxun, on the basis of previous research, built enterprise cultural values scale (VOCS scale). Zhang Mian of Tsinghua University based on the research of Quinn, combined with the actual culture China enterprises, established a special project group, developed by the 5 dimensions, and 20 items scale [9].

\section{National Cultural Distance (NCD) Measurement}

We picked Laszlo’s format as measurement method:

$$
\mathrm{CD}_{\mathrm{i}}=\sum_{5}^{=1}\left[\left(I_{i j}-I_{i u}\right)^{2} / V_{i}\right] / 5
$$

U: mother country;

$\mathrm{CD}_{\mathrm{j}}$ : cultural distance between country u and Coutry j;

$\mathrm{I}_{\mathrm{iu}}$ : country u's score in dimension I;

$\mathrm{V}_{\mathrm{i}}$ : the variance of dimension $\mathrm{i}$.

Also, as is shown in Table 2 below we collected the national cultural scores from Hofstede's website:

Table 2. National cultural distance between China and sample countries.

\begin{tabular}{ccccccccccc}
\hline & USA & UK & France & Australia & New Zealand & Japan & Korea & Brazil & Chile \\
\hline NCD & 5.486 & 5.723 & 4.703 & 5.486 & 4.774 & 5.158 & 2.233 & 2.102 & 2.313 \\
\hline
\end{tabular}

Source: Hofstede’s cultural dimension theory and Laszlo’s format. 


\section{Corporate Cultural Distance (CCD) Measurement}

We referenced Zhang Mian’s measurement model to measure the cultural distance. The measurement model starts from 5 dimensions: harmony, creation, short-term results, competition, control. We conduct the interviews through telephone, face-to-face, email, and media report. Then according to the statement, we score their corporate cultural distance. The results are displayed in Table 3.

Corporate culture measurement scale apply Linkert scoring method, the respondents have to score from completely conforms to the totally incompatible with the given 1 - 5 points. Through to the horizontal comparison of domestic and foreign enterprises, the absolute value is culture distance between enterprises.

Through the 16 cases, we get national cultural distance and cooperate cultural distance. Each set of data can be put into NCD-CCD matrix (Figure 1).

\section{Application of NCD and CCD in Cross Cultural State and Enterprise Culture Distance in Chinese Enterprises' Overseas M \& A Prudence Stage}

At the beginning of $\mathrm{M} \& \mathrm{~A}$, in addition of making strategy, searching target, choose a professional intermediary agencies, more priority should be on investigation the enterprise, namely cultural due diligence. At this stage, Chinese enterprises should consider establishing cultural due diligence team. The specific work can be done from the two aspects.

The differences between Chinese and western culture make Chinese enterprises attached great importance to the national cultural difference. Through the national cultural distance measurement, culture group can roughly assess cultural differences [10]. Therefore, by Hofstede's culture theory, Chinese enterprises can find the national cultural distance.

Cultural differences between China and the West are relatively easy to attract attention, but neglected the cultural differences of peripheral countries such as Japan to overseas M \& A process. Japan's culture IS born out of China, it has very deep origin. But due to the different process of political and economic development, Japan and other countries whose culture are derived from China, transformed to Western cultural essence. By previous analysis, 2.233 is China and Korean cultural distance. However, China and Japan cultural distance is up to 5.158. Therefore, in overseas M \& A, cultural prudential group should attach great importance to the cultural differences between different countries.

Table 3. Overseas M \& A NCD \& CCD score.

\begin{tabular}{ccc}
\hline Case & NCD & CCD \\
\hline BOE-Hyundai Display & 2.233 & 15 \\
Wanda-AMC & 5.486 & 24 \\
Shanghai electric-Japan Akiyama & 5.158 & 31 \\
China LAN-STAR-France Andy Sue & 4.703 & 17 \\
TCL-Thomson, France & 4.703 & 21 \\
Bright Food-UK WEETABIX & 5.723 & 32 \\
Bright food-Mamathan & 5.486 & 32 \\
SAIC-Ssangyong & 2.233 & 39 \\
Meidi-Carrier Latin America & 2.102 & 51 \\
Lenovo-Brazil CCE & 2.102 & 33 \\
Vigor-MLS & 2.313 & 57 \\
Vigor-SAM & 2.313 & 5 \\
Vigor-Maricunga & 2.313 & 45 \\
Vigor-TOKM & 4.774 & 42
\end{tabular}

Source: NCD figures are based on the M\&A related two countries and Laszlo’s format; CCD are based on the Zhang Mian’s measurement model. 


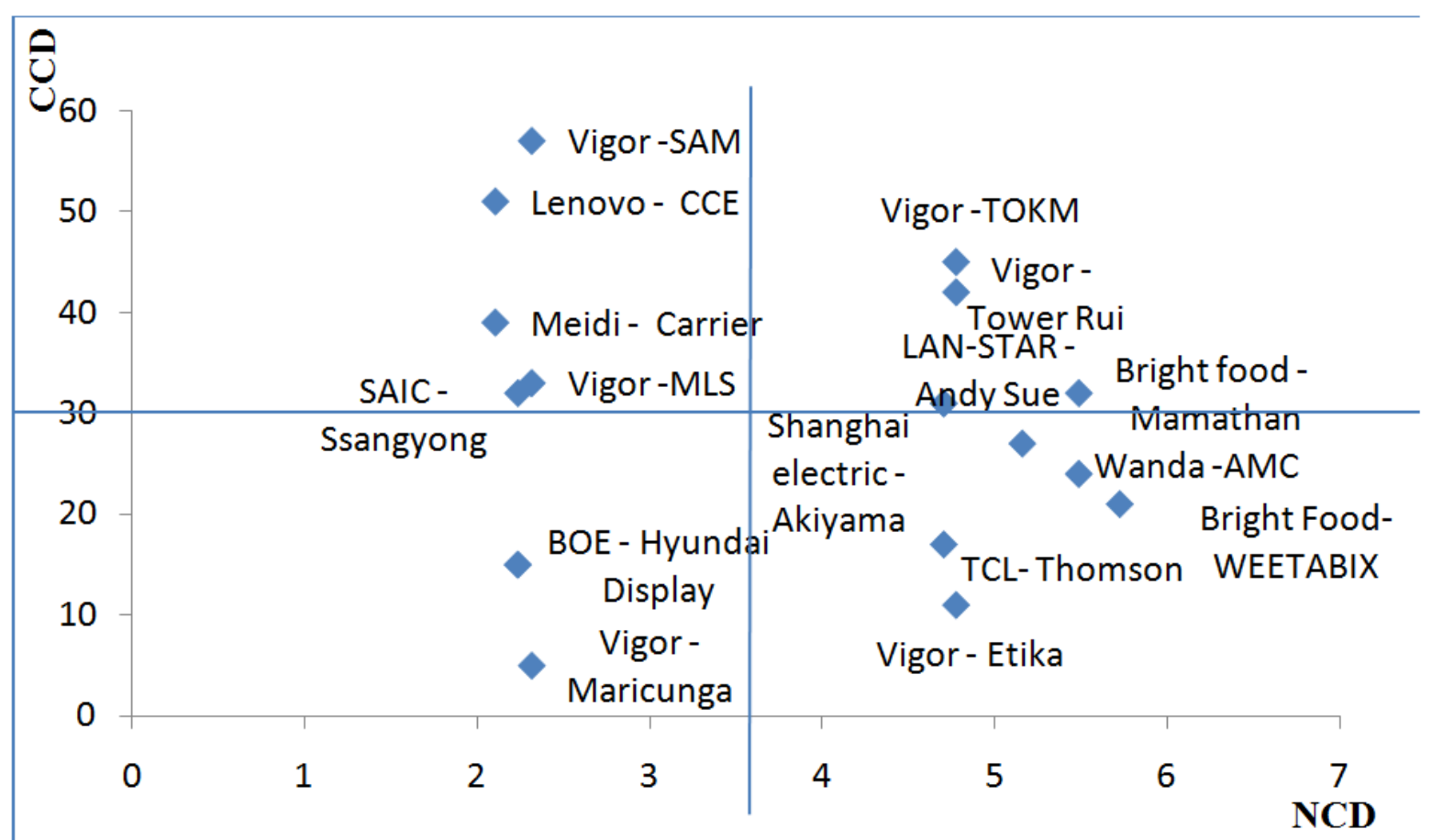

Figure 1. NCD-CCD Matrix. Source: NCD-CCD matrix is based on the numbers which are calculated with Laszlo's format and Zhang Mian's measurement model.

The M \& A in same country may experience failure caused by cultural difference. In different countries, different cultural background in two businesses will be more significant.

Investigation and Analysis on the enterprise culture is generally divided into two stages: before the information release and after information release. Before the $\mathrm{M} \& \mathrm{~A}$ announcement, enterprises often have a number of candidate target, prudential group need to conduct research for each target enterprises, so as to find out the perfect fit in culture. At this stage, because the information is closed, the investigation team can not directly contact with other enterprises. Only through various channels can they find the information. To be specific, information collection can be announced material, company website, advertising, management mechanism, annual report, commercial article, etc. Through all the channels of information collection, culture prudential group can locate the target enterprise culture. According to the culture measurement scale, CCD can be concluded. Then the team can make the budget for the integration of various feasible schemes. When the company announced acquisition information, the cultural enterprises of the investigation can be carried out. To obtain more accurate data, cultural survey information can be published results for inspected and corrected.

\section{Summary}

We calculated the 16 cases' NCD and CCD, and come to the matrix. In future work, we will use NCD-CCD matrix to study Chinese enterprises' overseas M\&A process in different quadrant and the coping strategies.

\section{Acknowledgements}

Supported by Innovation Program of Shanghai Municipal Education Commission (12ZS172), Humanities and Social Science Research Program Foundation of Ministry of Education of China (11YJA630162), and the research achievement also belongs to the Research Platform (Think-tank) Project of SUIBE in 2014.

\section{References}

[1] UNCTAD (2013) World Investment Report. 22-23.

[2] Luostarinen, R. (1980) Internationalization of the Firm. The Helsinki School of Economics, Helsinki, 334-335. 
[3] Lee, D.-J. (1998) The Effect of Cultural Distance on the Relational Exchange Between Exporters and Importers: The Case of Australian Exporters. Journal of Global Marketing, 11, 36-41. http://dx.doi.org/10.1300/J042v11n04_02

[4] Tihanyi, L. and Griffith, D.A. (2005) The Effect of Cultural Distance on Entry Mode Choice, International Diversification, and MNE Performance: A Meta-Analysis. Journal of International Business Studies, 36, 270-283. http://dx.doi.org/10.1057/palgrave.jibs.8400136

[5] Qu, X.R. (2011) An Empirical Study on the Influence of Cultural Distance: Chinese Cultural Products Trade. Heilongjiang Social Science, 27-34.

[6] Kogut, B. and Singh, H. (1988) The Effect of National Culture on the Choice of Entry Mode. Journal of International Business Studies, 19, 81-93. http://dx.doi.org/10.1057/palgrave.jibs.8490394

[7] Linda, M. and William, J.H. (2008) A Re-Inquiry of Hofstede’s Cultural Dimensions: A Call for 21st Century CrossCultural Research. Marketing Management Journal.

[8] O’Reilly, C.A. and Chatman, J. (1991) People and Organizational Culture Assessing Person Organizational Fit. Academy of Management Journal, 34, 487-516. http://dx.doi.org/10.2307/256404

[9] Zhang, M., Li, H. and Yan J.G. (2007) Construction and Empirical Study of Measurement Model of Organizational Culture. Journal of Safety Science and Technology, 12-30.

[10] O’Hara, D. and Johansen. R. (1994) Globalwork: Bridging Distance, Culture and Time. Jossey-Bass Publisher, San Francisco. 